\title{
BMJ Open Effect of a dementia education intervention on the confidence and attitudes of general practitioners in Australia: a pretest post-test study
}

\author{
Ron Mason (D) , ${ }^{1}$ Kathleen Doherty, ${ }^{1}$ Claire Eccleston, ${ }^{1}$ Margaret Winbolt, ${ }^{2}$ \\ Marita Long, ${ }^{1}$ Andrew Robinson ${ }^{1}$
}

To cite: Mason R, Doherty K, Eccleston C, et al. Effect of a dementia education intervention on the confidence and attitudes of general practitioners in Australia: a pretest posttest study. BMJ Open 2020;10:e033218. doi:10.1136/ bmjopen-2019-033218

- Prepublication history for this paper is available online. To view these files, please visit the journal online (http://dx.doi. org/10.1136/bmjopen-2019033218).

Received 27 July 2019 Revised 10 December 2019 Accepted 02 January 2020

D) Check for updates

(c) Author(s) (or their employer(s)) 2020. Re-use permitted under CC BY-NC. No commercial re-use. See rights and permissions. Published by BMJ.

${ }^{1}$ Wicking Dementia Research and Education Centre, University of Tasmania, Hobart, Tasmania, Australia

${ }^{2}$ Australian Centre for Evidence Based Aged Care, La Trobe University, Melbourne, Victoria, Australia

Correspondence to

Dr Ron Mason;

ron.mason@utas.edu.au

\section{ABSTRACT}

Objectives This study assessed the impact of a Dementia Education Workshop on the confidence and attitudes of general practitioner (GP) registrars (GPR) and GP supervisors (GPS) in relation to the early diagnosis and management of dementia.

Design Pretest post-test research design.

Setting Continuing medical education in Australia.

Participants 332 GPR and 114 GPS.

Interventions Registrars participated in a 3-hour face-toface workshop while supervisors participated in a 2-hourmodified version designed to assist with the education and supervision of registrars.

Main outcome measures The General Practitioners Confidence and Attitude Scale for Dementia was used to assess overall confidence, attitude to care and engagement. A t-test for paired samples was used to identify differences from preworkshop (T1) to postworkshop (T2) for each GP group. A t-test for independent samples was undertaken to ascertain differences between each workshop group. A Cohen's d was calculated to measure the effect size of any difference between $\mathrm{T} 1$ and $\mathrm{T} 2$ scores.

Results Significant increases in scores were recorded for Confidence in Clinical Abilities, Attitude to Care and Engagement between pretest and post-test periods. GPR exhibited the greatest increase in scores for Confidence in Clinical Abilities and Engagement.

Conclusions Targeted educational interventions can improve attitude, increase confidence and reduce negative attitudes towards engagement of participating GPs.

\section{INTRODUCTION}

General practitioners (GPs) are central to the early diagnosis and management of dementia. ${ }^{1}$ Early diagnosis provides the opportunity for patients, carers and family to be informed about the condition, its prognosis, treatment options and support ${ }^{23}$ and allows the patient to plan for their future and be active participants in decision-making. ${ }^{45}$

Obstacles to timely diagnosis and intervention may include a lack of diagnostic tests/certainty ${ }^{6}$ and lack of confidence in

\section{Strengths and limitations of this study}

- The sample of registrars and supervisors is representative of the broader general practitioner (GP) population in Australia.

- While the GP registrars' workshop was compulsory, this was not the case for GP supervisors; thus, selfselection bias is possible.

- Confidence, attitudes and engagement were measured via General Practitioners Confidence and Attitude Scale for Dementia, a validated tool.

- While each of the subscales included items relating to early diagnosis, the survey did not fully capture attitudes towards disclosure or perceived selfefficacy regarding communication.

diagnostic skills and management, ${ }^{7}$ while negative attitudes towards diagnosis, disclosure and treatment ${ }^{8-10}$ may also affect diagnosis rates. Further, stigma may delay recognition and diagnosis through concealment, minimisation or dismissal of early signs and symptoms. ${ }^{11}$ Patients often present with co-occurrent conditions, further complicating the clinical picture. ${ }^{3} 12$

It is estimated that one-third of GPs lack confidence in their diagnostic skills, while twothirds lack confidence in the management of behaviours associated with dementia, ${ }^{7}$ or feel they have little or nothing to offer patients presenting with dementia, ${ }^{13}$ with a third of GPs failing to routinely disclose the diagnosis. ${ }^{71415}$ Similarly, pessimism surrounding dementia prognosis, and inability to offer curative treatment ${ }^{16}$ may lead to an attitude of 'therapeutic nihilism' among GPs, ${ }^{71}$ which reflects a biomedical definition of treatment and an ethos centred around curing people, ${ }^{16}$ while simultaneously ignoring therapeutic interventions that may benefit people with dementia and their carers. ${ }^{17-19}$ 
Illiffe et al argue that low rates of dementia diagnosis are a result of knowledge and skills deficits and failure to transfer acquired knowledge into clinical practice. ${ }^{9}$ Relatedly, Boise et al state that attitude rather than knowledge is a key determinant of whether a GP undertakes a full assessment, ${ }^{2}$ and others argue that the diagnostic and management practices of GPs towards dementia may be significantly affected by underlying beliefs and attitudes. ${ }^{20}{ }^{21}$ While social psychological theory suggests a relationship between perceptions of self-efficacy, effort and avoidance, ${ }^{22}$ GPs hesitancy to diagnose dementia may not be explicit. Rather it may manifest in a reluctance to formalise a diagnosis or preferentially treat co-occurring conditions for which treatment options are available, ${ }^{10}{ }^{23}$ referring on because of limited treatment options, ${ }^{24}$ questioning the (traditional) role of the GP in treating dementia ${ }^{25}$ or having insufficient resources. ${ }^{15}$

Changing attitudes towards the early diagnosis of dementia has been identified as a significant task for medical educators, with the key to countering such attitudes being targeted educational campaigns. ${ }^{26}$ Moreover, evidence suggests that the focus of GP training around dementia should encompass more than knowledge acquisition and aim to improve confidence and attitude. ${ }^{27}$ While GP attitudes toward caring for people with dementia have been shown to be positive, ${ }^{28}$ fear of misdiagnosis ${ }^{6}$ and lack of confidence in diagnostic and dementia management skills have been reported to be of particular concern in multiple studies with a lack of effective education and training frequently cited as an underlying cause. ${ }^{72129}$

Comprehensive dementia education for GPs should include epidemiological knowledge, communicating a diagnosis, symptom management and support services for patients and their carers. ${ }^{30} 31$ Tullo and Allan ${ }^{32}$ emphasise the importance of personhood, quality of life and communication with patients, ${ }^{32}$ while Phillipson $e t a l^{33}$ argue that training interventions should place an emphasis on the slow progression of the condition, the treatments available and maintenance of quality of life. ${ }^{33}$

In Australia, GPs typically are trained in an apprenticeship model with a key aspect of training involving experienced GPs (supervisors) providing support to the GP registrar (GPR) within a general practice setting. Supervisors facilitate registrar learning through identifying learning needs, encouraging reflective learning and practice, guiding access to resources, providing advice on applying knowledge to specific patient cases and role modelling interactions with patients (22).

Tailored training workshops were developed specifically to augment this interaction and address dementia specific training needs. Directed at both supervisors and GPRs, we have previously shown them to be effective in improving dementia knowledge. ${ }^{34}$ Here, we examine the impact of these workshops on attitudes and confidence towards dementia with a view to improving management of dementia in general practice.

\section{METHOD}

\section{Study aims and design}

In Australia, GPRs are required to engage in a learning programme consisting of a number of learning units conducted by regional training providers in each state. 'The Recognising, Diagnosing and Managing Dementia in General Practice' workshop was developed by the Wicking Dementia Research and Education Centre as a response to the expressed absence of appropriate dementia related content in GPR training programme. Training was conducted at regional training offices in six Australian states (Tasmania, New South Wales, Victoria, Queensland, Australian Capital Territory and South Australia). The GPR workshop consists of a 3-hour faceto-face presentation delivered by medical educators focusing on (1) recognising and diagnosing dementia and (2) managing dementia in general practice. The supervisors' workshop, also conducted face to face and for similar durations, is a modified version of that delivered to registrars in that it seeks to support supervisors to teach registrars the diagnosis and management content provided in the registrar programme (see Tierney et $a \vec{l}^{34}$ ), with a more in-depth coverage of some aspects of dementia diagnosis and management in the registrars' workshop than in the supervisors workshop.

A strong focus on providing a framework for decisionmaking for the recognition, diagnosis and management of dementia is complemented by tools and resources that are aimed at improving both diagnostic capacity and providing ongoing care and support for people with dementia and their family and/or carers. In an attempt to address GPs reluctance to diagnose dementia, ${ }^{12}$ there is a strong focus on highlighting lived experience in order to situate people with dementia and their carers as central to the process, and to consider diagnosis and management through a biopsychosocial lens. ${ }^{3536}$ The intent is to facilitate GPs to engage with the process of diagnosis and associated management in a timely and supportive fashion.

\section{Sampling and participants}

Purposive sampling methods were employed to recruit participants from 18 dementia education workshops conducted in six Australian States between 2014 and 2018. Lists of GPs attending the GP registrar and supervisor workshops were provided by each regional training organisation and used as the sample frame for each region. The list comprised the GP's name and a unique ID number to ensure that each presurvey and postsurvey matched with the individual.

The sample comprised two cohorts; those who undertook the GP registrars workshop $(n=355)$ and those who undertook the supervisors workshop $(n=121)$. Of these groups, 332 GPRs and 114 supervisors completed the survey, representing a response rate of $93 \%$ and $94 \%$, respectively. The GPR workshop comprised recently graduated GPs (GPR) who were undertaking vocational training within a general practice setting, while the 
supervisor group comprised medical educators $(n=9)$, supervisors $(\mathrm{n}=87)$ and GPs $(\mathrm{n}=18)$.

\section{Process and measures}

The workshop was evaluated using a pretest post-test framework which employed two measures. Changes in knowledge of dementia were assessed using the Dementia Knowledge Assessment Survey (see Tierney et al ${ }^{34}$ ). This paper reports the second arm of the evaluation which used the General Practitioners Confidence and Attitude scale for Dementia (GPACS-D) survey $^{37}$ to evaluate the impact of the workshops on confidence and attitudes.

The GPACS-D comprises three subscales: Confidence in Clinical Abilities (six items), Attitude to Care (six items) and Engagement (three items); and is validated using confirmatory factor analysis. ${ }^{37}$ The GPACS-D is a reliable and valid measure of attitude and confidence change before and after targeted dementia education. A Likert scale is employed scoring from 1 (strongly agree) to 5 (strongly disagree). Total subscale scores are standardised with a minimum score of 1 and a maximum score of 5 so that comparisons can be made between subscales. ${ }^{38}$ The scoring system is described in detail in the study by Mason et $a .^{37}$

A research assistant not associated with delivery of the workshop administered the surveys. Pretest surveys were provided to each participant as they signed in along with an information sheet about the research. Attendees were informed that survey completion was entirely voluntary and that completion implied consent. Participants completed the surveys immediately before (T1) and immediately after (T2) the workshop, with each presurvey and postsurvey matched via the unique ID for each attendee.

\section{Ethics approval}

The Tasmania Social Sciences Human Research Ethics Committee (University of Tasmania) reviewed and approved this study (reference number: H0012046).

\section{Patient and public involvement}

There was no patient or public involvement in this study.

\section{Analysis}

We were interested in the impact of the respective workshops on GPRs and GP supervisors. We hypothesised that the supervisor group would differ from the GPR group in attitude and confidence given their experience as practising GPs.

Descriptive statistics were generated for demographic characteristics. Means and CIs were calculated for subscale scores and the individual items that made up each of the subscales, for both registrar and supervisor groups. We conducted t-tests for independent samples to identify differences between groups, while t-tests for paired samples were used to identify any significant differences in scores for each group between $\mathrm{T} 1$ and T2. t-tests are robust to violations of assumptions of normality. ${ }^{39} 40$ We applied Levene's test of equality of
Table 1 Sample characteristics - mean age and frequencies for gender, dementia training, providing professional care and family member with dementia

\begin{tabular}{lll}
\hline Demographics & $\begin{array}{l}\text { GP registrars } \\
(\mathbf{n}=332)\end{array}$ & $\begin{array}{l}\text { Supervisors } \\
(\mathbf{n}=114)\end{array}$ \\
\hline Age & $33.03(\mathrm{SD}=6.1)$ & $49.8(\mathrm{SD}=10.5)$ \\
\hline Male & $40.2 \%(\mathrm{n}=129)$ & $50 \%(\mathrm{n}=56)$ \\
\hline Australian born & $41.9 \%(\mathrm{n}=139)$ & $39.5 \%(\mathrm{n}=45)$ \\
\hline Previous dementia training & $5.6 \%(\mathrm{n}=18)$ & $20 \%(\mathrm{n}=22)$ \\
\hline Provided professional care & $87 \%(\mathrm{n}=280)$ & $98 \%(\mathrm{n}=108)$ \\
\hline Family member dementia & $35.5 \%(\mathrm{n}=114)$ & $38.2(\mathrm{n}=42)$ \\
\hline
\end{tabular}

GP, general practitioner.

variance to establish homogeneity of variance. Adjusted 'p' values were reported where heterogeneity of variance was identified.

Cohen's d was calculated to measure the effect size of any observed difference between $\mathrm{T} 1$ and $\mathrm{T} 2$ scores for each group with $\mathrm{d}=0.2$ equivalent to a 'small' effect size, 0.5 a 'medium' effect size and 0.8 or above a 'large' effect size. ${ }^{41}$ All data analyses were conducted using SPSS (V.22).

\section{RESULTS}

Four hundred and forty-six respondents were included in the analysis comprising 332 attendees at GPR workshops (the GPR group) and 114 attendees from the supervisor workshop (the supervisor group; table 1). Supervisors were significantly older than GPRs $(t(414)=21.121$; $\mathrm{p}<0.001)$, and more had undertaken prior dementia education $\left(\chi^{2}=20.263 ; \mathrm{p}<0.001\right)$, although this proportion was small for both groups. More supervisors had provided professional care to someone with dementia than GPRs $\left(\chi^{2}=11.294 ; \mathrm{p}=0.001\right)$, while similar proportions of both groups had a family member with dementia.

We compared age and gender in our sample (GPACS-D) with other samples containing registrars and or supervisors to gauge the representativeness of our sample. These included: The General Practice Supervisors Australia Survey $(2017)^{42}$ for Supervisor characteristics, and The Australian General Practice Training Program Survey $(2018)^{43}$ and Registrars' Clinical Encounters in Training $(2018)^{44}$ for Registrars. An examination of these samples revealed that the GPACS-D sample is broadly representative of the GP population. A slightly larger proportion of females was found in the supervisor group in the GPACS-D sample, while minimal differences emerged for age in both registrars and supervisor groups.

The GPACS-D assessed the impact of each of the workshops on three constructs: Confidence in Clinical Abilities, Attitude to Care and Engagement.

Items in the Confidence in Clinical Abilities subscale reflect a GP's perception of their capacity to diagnose, treat and manage dementia. Analysis of scores for each of the items comprising this subscale is shown in table 2. 


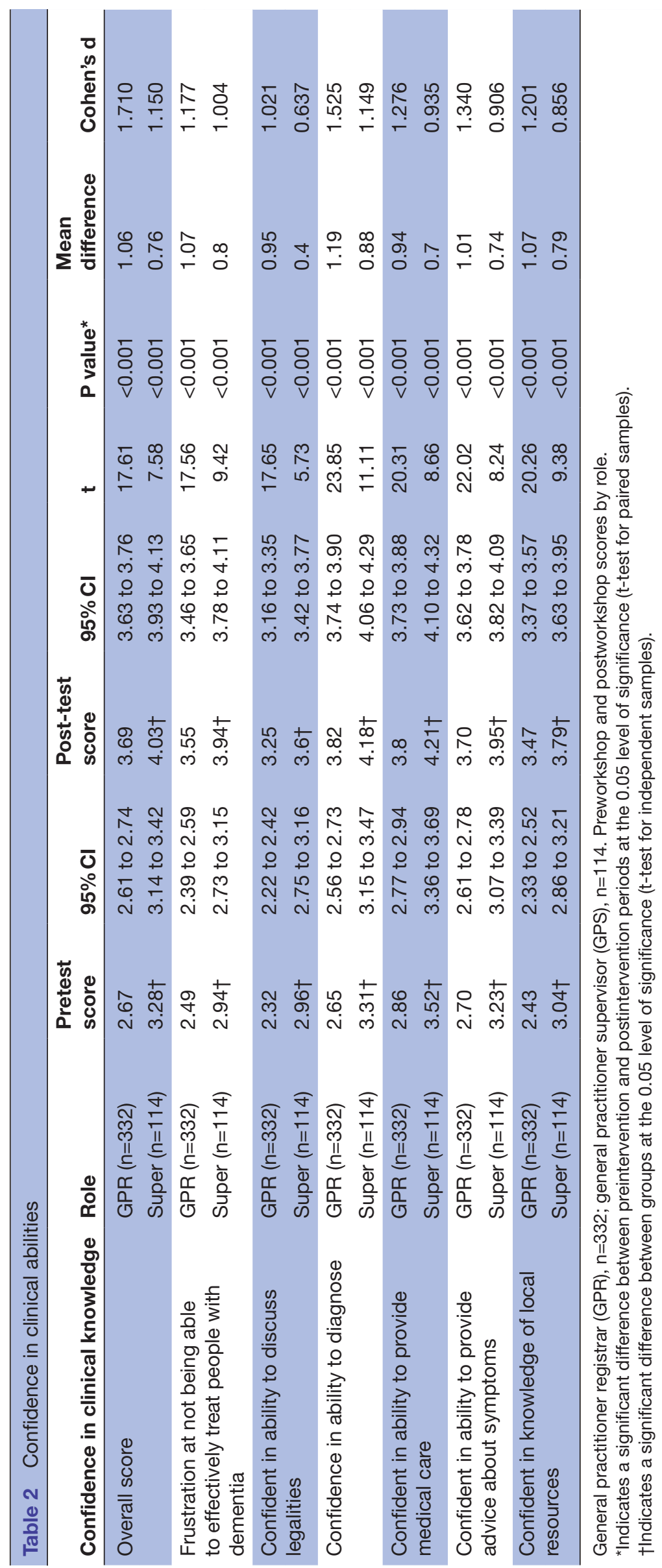


While both GPRs and supervisors were significantly more confident after the workshops, supervisors were significantly more confident in their clinical abilities than GPRs both before $(\mathrm{t}(438)=8.424 ; \mathrm{p}<0.001))$ and after their respective workshops $(\mathrm{t}(420)=5.328 ; \mathrm{p}<0.001)$. GPRs exhibited a significantly greater improvement in score than supervisors $(\mathrm{t}(414)=3.797 ; \mathrm{p}<0.001)$. The effect size of the change in Confidence in Clinical Abilities was strong for both groups and greatest for GPRs.

Before the workshop, only $13.8 \%$ of GPRs were 'confident (either strongly agreed or agreed) in their ability to diagnose' compared with $44.2 \%$ of supervisors, rising to $60.4 \%$ for GPRs postworkshop (62.6\% post for supervisors). A similar change occurred in the confidence of GPRs in their 'ability to provide appropriate medical care', with an increase in agreement (those strongly agreeing or agreeing) from $18.7 \%$ to $59.8 \%$ after the workshop. Further, only $13.8 \%$ of GPRs agreed or strongly agreed that they were confident in 'providing advice about managing dementia-related symptoms' preworkshop, compared with $48.5 \%$ of supervisors $(8.8 \%$ strongly agreed), increasing to $56.3 \%$ postworkshop for GPRs (9.5\% strongly agreed) and $67 \%$ for supervisors (27.4\% strongly agreed).

\section{Attitude to Care}

Items in the Attitude to Care subscale reflect aspects of the provision of care for patients and their families. Analysis of scores for each of the items comprising this subscale is shown in table 3.

Overall mean scores for Attitude to Care (table 3) were equivalent for supervisors and GPRs prior to the workshops and increased significantly for both GPRs and supervisors following the workshop, with moderate effect sizes for the increases. GPRs scored significantly higher than supervisors postworkshop $(\mathrm{t}(420)=2.463 ; \mathrm{p}=0.014)$.

Both groups reported significant increases in agreement that 'early detection of dementia benefits the patient', though the effect size for supervisors was weak. The greatest difference reported was for those strongly agreeing, with a $30.6 \%$ change for GPRs (47.3\% preworkshop to $77.9 \%$ postworkshop), and only an $18 \%$ increase for supervisors $(44.2 \%-62.6 \%)$. Similar results were obtained for the item 'Patients with dementia should be informed early so they can plan for the future', while both GPR and supervisor groups recorded increases in those agreeing or strongly agreeing that 'it is important that relatives/family/carers of dementia seek external support'.

\section{Engagement}

Engagement measures a GP's perceptions towards treating dementia, and includes fear of communicating a diagnosis, frustration in managing dementia and a preference for treating other conditions (table 4). Both supervisors and GPRs recorded a significantly higher score for Engagement postworkshop, while supervisors reported greater Engagement than GPRs at baseline $(\mathrm{t}(439)=5.877$; $\mathrm{p}<0.001)$ and after the workshop $(\mathrm{t}(422)=5.091 ; \mathrm{p}<0.001)$. A moderate effect size was observed for the score change shown for each group.

Both supervisors and GPRs showed an increase in the proportion disagreeing or strongly disagreeing with the statement that 'dementia was frustrating to manage' (19.5\%-39.4\% for GPRs; $31 \%-50.5 \%)$. However, a significant proportion of both groups were still undecided about this statement post workshop (GPRs 33.1\%; 19.6\% supervisors).

The proportion of GPRs agreeing or strongly agreeing to a 'preference for treating other diseases' decreased from $32 \%$ preworkshop to $18.6 \%$ postworkshop, compared with $18.6 \%-10.3 \%$ for supervisors. However, a large proportion of each group were neutral to the statement before and after the workshop, with a decreased proportion of supervisors $(42.5 \%$ pre, $32.7 \%$ post) and a relatively unchanged proportion of GPRs $(38.1 \%$ pre, $39 \%$ post) reporting neutral views on this item.

\section{DISCUSSION}

This study examined the impact of tailored dementia education workshops on the attitudes and confidence of both GPR and GP supervisors towards dementia. Attending tailored workshops resulted in significant improvements in attitudes, confidence and engagement of both groups. While increased confidence and reduced negative attitudes towards the management of dementia have previously been reported to correlate with a selfreported history of prior dementia training, ${ }^{17}$ this study demonstrates a direct and immediate impact of a training intervention.

In some respects, the positive Attitude to Care at baseline was not surprising given that GPs are reported to have a positive attitude with respect to their role in providing care and early diagnosis for people with dementia. ${ }^{28} 45$ However, the further improvements in this subscale shown after the workshop highlight the effectiveness of the workshop's focus on early warning signs and on the importance of diagnosis and management approaches, all of which are intended to influence participants to more effectively engage people with dementia and their families. These results suggest that workshop attendance is useful in preparing GPR for practice and may enhance practice in experienced GPs who act as their supervisors.

The confidence of the GPR group, while not as high as supervisors, significantly improved postworkshop, although from a notably low level. This improvement provides insight into the importance of targeting education beyond the traditional biomedical focus typical of much medical education, ${ }^{16}$ often with minimal focus on therapeutic interventions. ${ }^{17-19}$ Differences in pretest confidence between the cohorts are not surprising given GPRs are generally younger and less experienced. ${ }^{21}$ The greater magnitude of change for GPR in this study would suggest that elements restricted to the registrars' workshop, and perhaps in particular elements that teach skills 


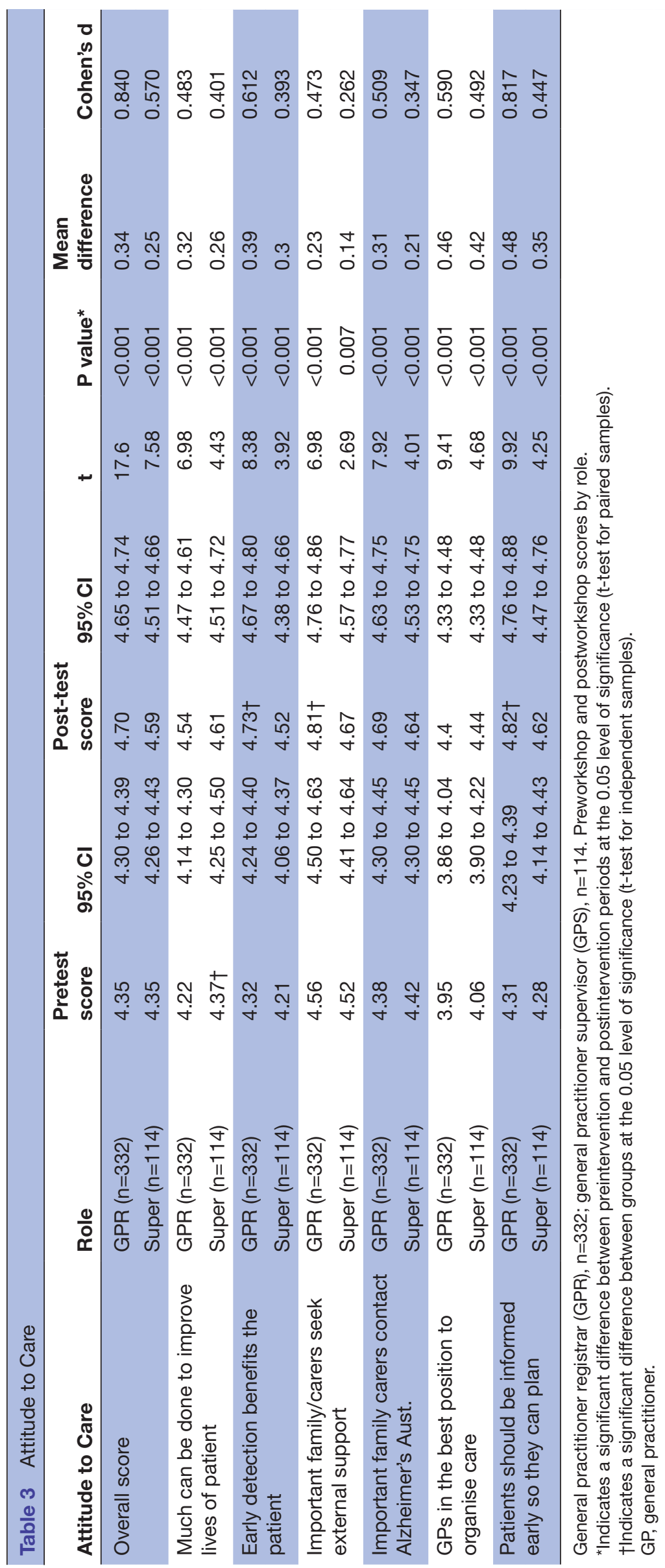


Table 4 Engagement

\begin{tabular}{|c|c|c|c|c|c|c|c|c|c|}
\hline Engagement & Role & $\begin{array}{l}\text { Pretest } \\
\text { score }\end{array}$ & $95 \% \mathrm{Cl}$ & $\begin{array}{l}\text { Post-test } \\
\text { score }\end{array}$ & $95 \% \mathrm{Cl}$ & $\mathbf{t}$ & $\begin{array}{l}\mathbf{P} \\
\text { value* }^{*}\end{array}$ & $\begin{array}{l}\text { Mean } \\
\text { difference }\end{array}$ & Cohen's d \\
\hline Overall score & GPR $(n=332)$ & 2.98 & 2.90 to 3.06 & 3.42 & 3.34 to 3.50 & 12.06 & $<0.001$ & 0.44 & 0.610 \\
\hline \multirow{2}{*}{$\begin{array}{l}\text { Managing dementia } \\
\text { frustrating }\end{array}$} & GPR $(n=332)$ & 3.00 & 2.91 to 3.10 & 3.51 & 3.40 to 3.61 & 9.23 & $<0.001$ & 0.37 & 0.569 \\
\hline & Super $(n=114)$ & $3.45 \dagger$ & 3.26 to 3.64 & $3.91 \dagger$ & 3.75 to 4.07 & 4.721 & $<0.001$ & 0.27 & 0.494 \\
\hline \multirow{2}{*}{$\begin{array}{l}\text { Preference for } \\
\text { treating other } \\
\text { diseases }\end{array}$} & GPR $(n=332)$ & 2.77 & 2.66 to 2.87 & 3.2 & 3.09 to 3.31 & 8.87 & $<0.001$ & 0.42 & 0.440 \\
\hline & Super $(n=114)$ & $3.27 \dagger$ & 3.09 to 3.45 & $3.64 \dagger$ & 3.46 to 3.31 & 5.09 & $<0.001$ & 0.4 & 0.355 \\
\hline
\end{tabular}

General practitioner registrar (GPR), n=332; general practitioner supervisor (GPS), $n=114$. Preworkshop and postworkshop scores by role.

*Indicates a significant difference between preintervention and postintervention periods at the 0.05 level of significance ( $t$-test for paired samples).

†Indicates a significant difference between groups at the 0.05 level of significance (t-test for independent samples).

in diagnosis, provision of appropriate medical care and management of dementia-related symptoms, may particularly impact on confidence, again highlighting its applicability to GP specialty training.

However, it is interesting that only $44 \%$ of supervisors reported confidence to diagnose dementia preworkshop, rising to only around $60 \%$ postworkshop. Similar findings were evident in the items related to confidence providing advice and appropriate medical care. It was also notable that at both preworkshop and postworkshop periods registrars had more positive attitudes about the benefits of early diagnosis than supervisors. This finding may be influenced by the supervisors' underlying beliefs and attitudes, ${ }^{20} 21$ which in turn may delay diagnosis in practice, particularly given attitudes rather than knowledge have been identified as a key determinant of whether a GP undertakes a full assessment. ${ }^{2}$ Addressing these gaps is essential if GP supervisors are to effectively support GP Registrars to develop their dementia diagnostic and management skills in the clinic in the context of the apprenticeship model of GP training used in Australia. ${ }^{464}$

A positive impact on engagement was also observed, with both groups recording significantly improved scores after each of the workshops. The higher scores for the GP supervisors group may in part reflect their level of exposure and experience to dementia. However, it is concerning that preworkshop only $31 \%$ of supervisors disagreed with the statement 'dementia is frustrating to manage', with $19.5 \%$ of GPRs disagreeing. While these scores improved post workshop, this does suggest a high level of frustration. ${ }^{38}$ Indeed, the literature suggests GPs' perceptions of their capacity to diagnose, communicate a diagnosis and manage dementia may impact on the extent to which they engage with a person with suspected or actual dementia or how much effort they apply to it. ${ }^{38}$

Of note, GPRs commenced the workshop with a low likelihood of having experienced any prior dementia training, despite $87 \%$ having provided professional care to people with dementia. This lack of training has implications for the GPs' knowledge of dementia, as we have previously demonstrated. ${ }^{1}$ Results reported recently suggest that particularly for GPRs, the workshop increases their base knowledge of dementia. ${ }^{1}$ It is possible that this is related to their increased confidence levels as demonstrated in this study. Educational and health literature indicates that knowledge is typically correlated with both attitudes and perceptions of self-efficacy. ${ }^{48}$ Taken together, the positive impacts of these workshops may translate to improved diagnosis rates and/or support to people with dementia.

It is clear that effective educational interventions involve more than knowledge and skills acquisition. ${ }^{27}$ In particular, designing educational initiatives requires a cognisance of clinical issues and the values, attitudes and experiences of those being trained. In this context, findings from this study can be used to identify specific components of attitude and confidence that may be able to be targeted in future workshops. This point is especially important given the importance placed on attitudes in relation to how a GP approaches dementia. GPs tend to be knowledgeable about dementia, ${ }^{9}{ }^{26}$ but low rates of diagnosis persist, ${ }^{10}$ suggesting that more than simply knowledge is involved, and that a GP's attitude towards the benefits of diagnosis, support and management is essential for effective clinical practice.

In consideration of this, educational interventions should aim to change the way GPs view dementia and their role in managing the condition. Such interventions should support GP's adoption of therapeutic approaches to treatment and management rather than a purely medical one with a curative focus, with the overall aim of increasing engagement between the GP, the person with dementia and their families or carer. 
While this study provides insights into confidence and attitudes as these relate to the diagnosis and management of dementia and the effectiveness of educational interventions on confidence and attitudes, there were some limitations. For supervisors, there was the likelihood of self-selection bias given that they volunteered for the workshop. For participating registrars, the workshop was a part of their compulsory training programme.

The study design was pre and post, measuring impact of the workshop. It is possible, as with any pre-post survey research, that response bias may have resulted from the perceived need for socially desirable responses on the part of the participant. However, there were no incentives for bias, survey responses were anonymous, and items were non-leading.

Our study was focused on the immediate impact of the workshops on the confidence and attitudes of participants. Future research should focus on providing evidence of the impact of the workshop on changes in behaviour as it relates to the diagnosis and management of dementia. Additionally, communication has been identified as a crucial part of the diagnostic procedure. While we did address some aspects of communication, survey items did not fully capture the construct ${ }^{37}$; therefore, more work is required in this area given its importance in relation to providing a diagnosis and the doctor-patient relationship.

\section{CONCLUSION}

Targeted educational interventions can improve attitude, increase confidence and reduce negative attitudes towards engagement of participating GPR and supervisors. Findings highlight a clear need for GPs to have access to targeted workshops especially given the growing numbers of people with dementia.

Acknowledgements The authors would like to acknowledge the significant contribution made by Dr Amanda Lo in developing the GP workshops.

Contributors Study design: MW and AR. Data collection: RM. Data analysis and interpretation: RM, KD and CE. Drafting the article: RM. Critical revision of the article: all authors. Final approval: all authors.

Funding This project was funded by the Australian Government Department of Health through the Victorian and Tasmanian Dementia Training Study Centre (DTSC) until 2016 and then Dementia Training Australia (DTA) from 2016. The study design was developed by the Wicking Dementia Research and 29 Education Centre (WDREC) and submitted to the funder (DTSC and DTA) for approval. Data collection, analysis, interpretation and reporting were undertaken by the WDREC in partnership with Margaret Winbolt from La Trobe University, who was Director of the DTSC and is the Director of DTA. All authors had full access to all the data (including statistical reports and tables) in the study and can take responsibility for the integrity of the data and the accuracy of the data analysis.

Competing interests None declared.

Patient consent for publication Not required.

Provenance and peer review Not commissioned; externally peer reviewed.

Data availability statement № data are available. The data set is not available as ethics approval does not allow release.

Open access This is an open access article distributed in accordance with the Creative Commons Attribution Non Commercial (CC BY-NC 4.0) license, which permits others to distribute, remix, adapt, build upon this work non-commercially, and license their derivative works on different terms, provided the original work is properly cited, appropriate credit is given, any changes made indicated, and the use is non-commercial. See: http://creativecommons.org/licenses/by-nc/4.0/.

\section{ORCID iD}

Ron Mason http://orcid.org/0000-0002-7270-3843

\section{REFERENCES}

1 Geldmacher DS, Kerwin DR. Practical diagnosis and management of dementia due to Alzheimer's disease in the primary care setting: an evidence-based approach. Prim Care Companion CNS Disord 2013;15. doi:10.4088/PCC.12r01474. [Epub ahead of print: 29 Aug 2013].

2 Connell CM, Boise L, Stuckey JC, et al. Attitudes toward the diagnosis and disclosure of dementia among family caregivers and primary care physicians. Gerontologist 2004;44:500-7.

3 Pathak KP, Montgomery A. General practitioners' knowledge, practices, and obstacles in the diagnosis and management of dementia. Aging Ment Health 2015;19:912-20.

4 Bamford C, Lamont S, Eccles M, et al. Disclosing a diagnosis of dementia: a systematic review. Int $J$ Geriatr Psychiatry 2004;19:151-69.

5 Ford E, Greenslade N, Paudyal P, et al. Predicting dementia from primary care records: a systematic review and meta-analysis. PLoS One 2018;13:e0194735.

6 Milne A. Dementia screening and early diagnosis: the case for and against. Health Risk Soc 2010;12:65-76.

7 Cahill S, Clark M, O'Connell H, et al. The attitudes and practices of general practitioners regarding dementia diagnosis in Ireland. Int $J$ Geriatr Psychiatry 2008;23:663-9.

8 Koch T, Iliffe S. Rapid appraisal of barriers to the diagnosis and management of patients with dementia in primary care: a systematic review. BMC Fam Pract 2010;11:1.

9 Iliffe S, Manthorpe J, Eden A. Sooner or later? issues in the early diagnosis of dementia in general practice: a qualitative study. Fam Pract 2003;20:376-81.

10 van Hout H, Vernooij-Dassen M, Bakker K, et al. General practitioners on dementia: tasks, practices and obstacles. Patient Educ Couns 2000;39:219-25.

11 Vernooij-Dassen MJFJ, Moniz-Cook ED, Woods RT, et al. Factors affecting timely recognition and diagnosis of dementia across Europe: from awareness to stigma. Int $J$ Geriatr Psychiatry 2005;20:377-86.

12 Hansen EC, Hughes C, Routley G, et al. General practitioners' experiences and understandings of diagnosing dementia: factors impacting on early diagnosis. Soc Sci Med 2008;67:1776-83.

13 Mclntosh IB, Swanson V, Power KG, et al. General practitioners' and nurses' perceived roles, attitudes and stressors in the management of people with dementia. Health Bulletin-scottish Office Department Of Health 1999;57:35-43.

14 Lahjibi-Paulet H, Dauffy A, Minard A, et al. Attitudes toward Alzheimer's disease: a qualitative study of the role played by social representation on a convenient sample of French general practitioners. Aging Clin Exp Res 2012;24:384-90.

15 Somme D, Gautier A, Pin S, et al. General practitioner's clinical practices, difficulties and educational needs to manage Alzheimer's disease in France: analysis of national telephone-inquiry data. BMC Fam Pract 2013;14:81.

16 Gibbins J, McCoubrie R, Forbes K. Why are newly qualified doctors unprepared to care for patients at the end of life? Med Educ 2011;45:389-99.

17 Bradford A, Kunik ME, Schulz P, et al. Missed and delayed diagnosis of dementia in primary care: prevalence and contributing factors. Alzheimer disease and associated disorders 2009;23:306.

18 Gerritsen DL, Oyebode J, Gove D. Ethical implications of the perception and portrayal of dementia. Dementia 2016;1471301216654036.

19 Aminzadeh F, Molnar FJ, Dalziel WB, et al. A review of barriers and Enablers to diagnosis and management of persons with dementia in primary care. Canadian Geriatrics Journal 2012;15:85.

20 Perry M, Drašković I, van Achterberg T, et al. Development and validation of quality indicators for dementia diagnosis and management in a primary care setting. $J$ Am Geriatr Soc 2010;58:557-63.

21 Ahmad S, Orrell M, Iliffe S, et al. Gps' attitudes, awareness, and practice regarding early diagnosis of dementia. Br J Gen Pract 2010;60:e360-5.

22 Hawkins RMF. Self-Efficacy: a predictor but not a cause of behavior. J Behav Ther Exp Psychiatry 1992;23:251-6.

23 Kaduszkiewicz H, Bachmann C, van den Bussche $\mathrm{H}$. Telling "the truth" in dementia-Do attitude and approach of general practitioners and specialists differ? Patient Educ Couns 2008;70:220-6. 
24 Yaffe MJ, Orzeck P, Barylak L. Family physicians' perspectives on care of dementia patients and family caregivers. Canadian Family Physician 2008;54:1008-15.

25 Jennings AA, Foley T, Walsh KA, et al. General practitioners' knowledge, attitudes, and experiences of managing behavioural and psychological symptoms of dementia: a mixed-methods systematic review. Int J Geriatr Psychiatry 2018.

26 Meuser TM, Boise L, Morris JC. Clinician beliefs and practices in dementia care: implications for health educators. Educ Gerontol 2004;30:491-516.

27 Surr CA, Gates C, Irving D, et al. Effective dementia education and training for the health and social care workforce: a systematic review of the literature. Rev Educ Res 2017;87:966-1002.

28 Thyrian JR, Hoffmann W. Dementia care and general physicians--a survey on prevalence, means, attitudes and recommendations. Cent Eur J Public Health 2012;20:270-5.

29 Turner S, lliffe S, Downs M, et al. General practitioners' knowledge, confidence and attitudes in the diagnosis and management of dementia. Age Ageing 2004;33:461-7.

30 Iliffe S, Wilcock J, Austin T, et al. Dementia diagnosis and management in primary care developing and testing educational models. Dementia 2002;1:11-23.

31 Foley T, Boyle S, Jennings A, et al. "We're certainly not in our comfort zone": a qualitative study of GPs' dementia-care educational needs. BMC Fam Pract 2017;18:66.

32 Tullo E, Allan L. What should we be teaching medical students about dementia? Int Psychogeriatr 2011;23:1044-50.

33 Phillipson L, Magee C, Jones S, et al. Dementia attitudes and helpseeking intentions: an investigation of responses to two scenarios of an experience of the early signs of dementia. Aging Ment Health 2015;19:968-77.

34 Tierney L, Mason R, Doherty K, et al. Workshops on diagnosis and management of dementia for general practitioners: a prepost intervention study of dementia knowledge. BMJ Open 2019;9:e027804.
35 Engel GL. The clinical application of the biopsychosocial model. Am J Psychiatry 1980;137:535-44.

36 Jackson JS, Antonucci TC, Brown E. A cultural lens on biopsychosocial models of aging. Advances in cell aging and gerontology 2003;15:221-41.

37 Mason R, Doherty K, Eccleston C, et al. General practitioners attitude and confidence scale for dementia (GPACS-D): confirmatory factor analysis and comparative subscale scores among GPs and supervisors. BMC Fam Pract 2019;20:6.

38 Bandura A. Health promotion from the perspective of social cognitive theory. Psychol Health 1998;13:623-49.

39 Field A. Discovering statistics using IBM SPSS statistics. Sage 2013.

40 Tabachnick BG, Fidell LS, Osterlind SJ. Using multivariate statistics 2001.

41 Fritz CO, Morris PE, Richler JJ. Effect size estimates: current use, calculations, and interpretation. J Exp Psychol 2012;141:2-18.

42 Australia GPS. National GP Supevisor survey 2017.

43 Taylor R, Radloff A, Edwards E. Australian general practice training program 2017. National report on the.

44 Magin P, Morgan S, Henderson K, et al. Family medicine trainees' clinical experience of chronic disease during training: a crosssectional analysis from the registrars' clinical encounters in training study. BMC Med Educ 2014;14:260.

45 Milne AJ, Hamilton-West K, Hatzidimitriadou E. Gp attitudes to early diagnosis of dementia: evidence of improvement. Aging Ment Health 2005;9:449-55.

46 Wearne S, Dornan T, Teunissen PW, et al. General practitioners as supervisors in postgraduate clinical education: an integrative review. Med Educ 2012;46:1161-73.

47 Practitioners TRACoG. Curriculum for Australian general practice: users guide 2018, 2018.

48 McCall LM, Clarke DM, Rowley G. Does a continuing medical education course in mental health change general practitioner knowledge, attitude and practice and patient outcomes. Primary Care Mental Health 2004;2:13-22. 